\title{
KARAKTERISTIK SISTEM REFRIGERASI KOMPRESI UAP DENGAN REFRIGERANT CAMPURAN MUSICOOL 134 - $\mathrm{CO}_{2}$
}

\author{
Bagiyo Condro Purnomo ${ }^{1}$, Muji Setiyo ${ }^{2}$,* \\ ${ }^{1,2}$ Program Studi Mesin Otomotif, Fakultas Teknik, Universitas Muhammadiyah Magelang \\ Jl.Mayjend Bambang Soegeng KM.05 Mertoyudan Magelang \\ *E-mail: setiyo.muji@ummgl.ac.id
}

\begin{abstract}
ABSTRAK
Penelitian ini membahas penggantian refrigeran $R-134$ a yang berpotensi ODP dan GWP dengan refrigeran campuran Musicool $134-\mathrm{CO}_{2}$ pada sistem refrigerasi kompresi uap yang diaplikasikan pada sistem AC mobil. Karekteristik sistem AC diamati pada variasi putaran blower sebagai beban pendinginan dan variasi komposisi refrigeran $\mathrm{CO}_{2}$ pada Musicool $134\left(0 \% \mathrm{CO}_{2}, 1,5 \% \mathrm{CO}_{2}\right.$ dan 3\% $\left.\mathrm{CO}_{2}\right)$. Pada konfigurasi tersebut, dilakukan pengukuran temperatur dan tekanan refrigeran. Hasil penelitian menunjukkan bahwa refrigeran Musicool 134 yang dicampur dengan $\mathrm{CO}_{2}$ memberikan kinerja yang menjanjikan sebagai pengganti $\mathrm{R}-134 a$.
\end{abstract}

Kata kunci: Reftrofit, Refrigerant Musicool 134, Refrigeran $\mathrm{CO}_{2}$

\begin{abstract}
This study discusses the replacement of R-134a refrigerant which has the ODP and GWP by Musicooll 34 mixed with $\mathrm{CO}_{2}$ refrigerant in vapor compression refrigeration system which is applied to the car air conditioning systems. The characteristics performance of $A C$ was observed in the variation of blower speed as the cooling load and variations of composition of the $\mathrm{CO}_{2}$ refrigerant to Musicool $134\left(0 \% \mathrm{CO}_{2}, 1.5 \% \mathrm{CO}_{2}\right.$ and $\left.3 \% \mathrm{CO}_{2}\right)$. In this configuration, the temperature and pressure of the refrigerant was measured at the transient and steadystate conditions. The results showed that the Musicool 134 refrigerant mixed with $\mathrm{CO}_{2}$ provides a promising performance as an alternative refrigerant for $R-134 a$.
\end{abstract}

Keywords: Retrofit, Musicool 134 refrigerant, $\mathrm{CO}_{2}$ Refrigerant

\section{PENDAHULUAN}

Dalam dekade terakhir, ozone depleting potential (ODP) dan global warming potential (GWP) menjadi masalah serius yang harus dipertimbangkan dalam pengembangan refrigeran (Dalkilic \& Wongwises 2010; Sarkar \& Bhattacharyya 2009; Han et al. 2013; Pérez-García et al. 2013). Refrigeran chlorofluorocarbons (CFCs) dan hydrochlorofluorocarbons (HCFCs) secara bertahap dikurangi dan digantikan oleh refrigeran generasi baru. Refrigeran komersial yang digunakan dalam beberapa dekade terakhir dan efeknya pada lingkungan disajikan pada tabel 1 (Wang et al. 2010; Li et al. 2014).

Sebenarnya, refrigeran CFCs dan HCFCs memiliki kinerja yang baik dan dapat diterapkan secara luas pada berbagai model 
sistem AC dan sistem refrigerasi lain selama bertahun tahun (Mahajan \& Borikar 2014; Brown et al. 2002; Nagalakshmi \& Yadav 2014; Yadav \& Sharma 2015). Namun demikian, kedua refrigerant tersebut (CFCs dan HCFCs) memiliki berkontribusi terhadap penipisan ozon dan pemanasan global. Bahkan, Protokol Kyoto telah membatasi produksi dan penggunaan refrigeran yang memiliki dampak pada lingkungan tersebut (United Nations 1998). Oleh karena itu, para peneliti mengembangkan refrigeran ramah lingkungan yang berbasis pada hidrokarbon (HC) seperti propana, iso-butana, n-butana, atau campuran dari beberapa hidrokarbon sebagai fluida kerja pada sistem refrigerasi dan sistem AC mobil.

Tabel 1. Properti beberapa refrigeran (Wang et al. 2010)

\begin{tabular}{|c|c|c|c|c|c|c|}
\hline Refrigerants & $\begin{array}{l}\mathrm{R} 134 \mathrm{a} \\
(\mathrm{HFC})\end{array}$ & $\mathrm{R} 290(\mathrm{HC})$ & $\mathrm{R} 600 \mathrm{a}(\mathrm{HC})$ & $\begin{array}{l}\text { R290/R600a } \\
\text { mixture }(H C)\end{array}$ & $\begin{array}{l}\text { R152a } \\
(\mathrm{HFC})\end{array}$ & $\begin{array}{l}\text { R1234yf } \\
\text { (HFO) }\end{array}$ \\
\hline Global Warming Potential (GWP) & 1400 & 11 & 8 & 7 & 140 & 4 \\
\hline Ozone Depletion Potential (ODP) & 0 & 0 & 0 & 0 & 0 & 0 \\
\hline Atmospheric Life Time (years) & 14 & $<1$ & $<1$ & $<0.04$ & 2 & $<0.05$ \\
\hline $\begin{array}{l}\text { Acute Toxicity Exposure Level (ATEL) } \\
(\mathrm{ppm})\end{array}$ & 50,000 & 50,000 & 25,000 & 40,000 & 50,000 & 101,000 \\
\hline Lower Flammability Limit (LFL) (vol.\%) & - & 2.2 & 1.7 & 2.0 & 3.9 & 6.5 \\
\hline $\begin{array}{l}\text { Minimum Ignition Energy (MIE) (mJ)/Safety } \\
\text { Group }\end{array}$ & $-/ \mathrm{A} 1$ & $0.25 / \mathrm{A} 3$ & $0.25 / \mathrm{A} 3$ & N/A/A3 & $0.38 / \mathrm{A} 2$ & $>1000 / \mathrm{A} 2 \mathrm{~L}$ \\
\hline Molar Mass (kg/kmol) & 102.03 & 44.096 & 58.122 & N/A & 66.051 & N/A \\
\hline Vapor Density at $25{ }^{\circ} \mathrm{C}\left(\mathrm{kg} / \mathrm{m}^{3}\right)$ & 32.35 & 20.65 & 9.12 & N/A & 18.47 & N/A \\
\hline Critical Temperature $\left({ }^{\circ} \mathrm{C}\right)$ & 101.1 & 96.8 & 135 & 114.8 & 113.3 & N/A \\
\hline Critical Pressure (kPa) & 4061 & 4247 & 3647 & 4040 & 4522 & N/A \\
\hline Normal Boiling Point (NBP) $\left({ }^{\circ} \mathrm{C}\right)$ & -26.11 & -42.11 & -11.78 & -31.5 & -24.0 & N/A \\
\hline Vapor $\mathrm{Cp}$ at $25^{\circ} \mathrm{C}(\mathrm{kJ} / \mathrm{kg} \mathrm{K})$ & 1.0316 & 2.0724 & 1.8189 & 1.77 & 1.2536 & 1.0 \\
\hline
\end{tabular}

Hidrokarbon (HC) sebagai refrigeran alternatif untuk CFCs dan HFCs telah lama diujicobakan dan sekarang banyak diterapkan. Propane (R-290) dan butane (R-600) adalah hidrokarbon yang memiliki sifat kunci sebagai refrigeran. Alsaad and Hammad (1998) melakukan studi tentang penggunaan campuran tiga hidrocarbon (R-290/R-600/R600a) sebagai pengganti refrigerant R-12. Campuran $24,4 \%$ propana, $56,4 \%$ butana, dan $17,2 \%$ iso-butane tidak menyebabkan ODP. Suhu evaporator mampu mencapai $-15{ }^{\circ} \mathrm{C}$ dengan nilai COP 3,4 pada suhu kondensor 27 ${ }^{\circ} \mathrm{C}$ dan suhu lingkungan $20^{\circ} \mathrm{C}$. Austin, Kumar and Kanthavelkumaran (2012) juga meneliti refrigeran propana-butane untuk menggantikan R-134a. Hasil penelitian ini menunjukkan campuran refrigeran tersebut menghasilkan kinerja setara dengan R-134a. suhu evaporator mencapai $-20{ }^{\circ} \mathrm{C}$ dengan COP 6,4 pada suhu lingkungan $30^{\circ} \mathrm{C}$.

Campuran R-290/R-600 sebagai refrigeran alternatif untuk R-134a juga diselidiki oleh Wongwises and Chimres
(2005). Percobaan dilakukan dalam komposisi yang berbeda tetapi pada suhu lingkungan tetap pada $25{ }^{\circ} \mathrm{C}$. Campuran R-290/R-600 dengan $60 \% / 40 \%$ telah menunjukkan kinerja yang setara dengan R-134a. Sementara itu, Agrawal and Matani (2013) melakukan studi analisis kinerja sistem refrigerasi kompresi uap menggunakan R290/R600a juga untuk menggantikan R134a. Hasil penelitian ini menunjukkan bahwa COP dari R290/R600a lebih tinggi dari R134a pada tekanan $80 \mathrm{Lb} / \mathrm{In}^{2}$ dan diameter kapiler 0,5 Inc. Penelitian lain juga telah dilakukan oleh Dalkilic and Wongwises (2010) dengan refrigeran R-290/ R-600 pada pencampuran rasio 40\%/60\% untuk menggantikan R-12. Baru baru ini, campuran propana dan butana (LPG) juga diteliti oleh Setiyo et al. (2016) pada sistem AC mobil hibrida menggunakan sistem setengah siklus. Bahkan juga telah diaplikasikan pada katup ekspansi dari material PTFE (Setiyo et al. 2017).

Di Indonesia, refrigeran hidrocarbon yang sudah dikomersialkan adalah produk 
Pertamina dengan nama MUSICOOL yang memiliki keunggulan antara lain (Globalindo Niaga Prima):

1. Memiliki Sifat Fisika dan Thermodinamika yang lebih baik,

2. Sangat ramah lingkungan, tidak merusak lapisan Ozon dan tidak menimbulkan Efek Rumah Kaca,

3. Familiar dengan kehidupan manusia,

4. Kompatible terhadap semua mesin pendingin yang biasa menggunakan Refrigeran Sintetis,

5. Tidak merusak komponen Mesin AC,

6. Tidak perlu penggantian komponen peralatan AC,

7. Produk dalam negeri bahan baku banyak, Supply terjamin, serta Backup teknis tersedia.

Refrigeran Musicool juga sudah mengikuti prosedur keamanan dan keselamatan pada British Standard/BS 4434, AS/NZS-1677, SNI 06-6500-2000, SNI 066511-2000, dan SNI 06-6512-2000.

Meskipun tidak berefek pada ODP dan GWP, refrigerant hidrokarbon (HC) mempunyai kelemahan yaitu nilai mampu bakar (flammable) yang cukup tinggi dibandingkan refrigeran yang lain. Untuk mengatasi sifat mampu bakar tersebut harus dicampur dengan senyawa inhibitor, yakni suatu senyawa yang dapat menghambat laju reaksi pembakaran. Gas inert, seperti nitrogen $\left(\mathrm{N}_{2}\right)$ dan karbondioksida $\left(\mathrm{CO}_{2}\right)$, dapat berfungsi sebagai inhibitor dalam reaksi pembakaran (Liao et al. 2005). Dari hasil penelitian tersebut, $\mathrm{CO}_{2}$ memiliki kemampuan sebagai inhibitor yang lebih baik dibandingkan dengan $\mathrm{N}_{2}$, sehingga lebih menjanjikan untuk digunakan sebagai gas inhibitor dalam penggunaan hidrokarbon sebagai refrigeran. Untuk itu, makalah ini menyajikan karakteristik refrigeran Musicool M134 yang dicampur $\mathrm{CO}_{2}$ pada sistem $\mathrm{AC}$ kendaraan.

\section{METODE PENELITIAN}

Lingkup penelitian ini mencakup dua variabel bebas yaitu komposisi refrigerant dan putaran blower. Pada konfigurasi tersebut dilakukan pengukuran temperatur dan tekanan pada setiap titik uji seperti pada gambar 1 . Pengukuran dilakukan dalam rentang 0 detik sampai 300 detik dengan variabel konsentrasi $\mathrm{CO}_{2}$ pada $0 \%, 1,5 \%$ dan $3 \%$ terhadap berat keseluruhan, kecepatan putar blower pada low
(14755 CMM), medium (17900 CMM) dan high (22850 CMM). Set up peralatan dan madia uji disajikan pada Gambar 1 sebagai berikut.

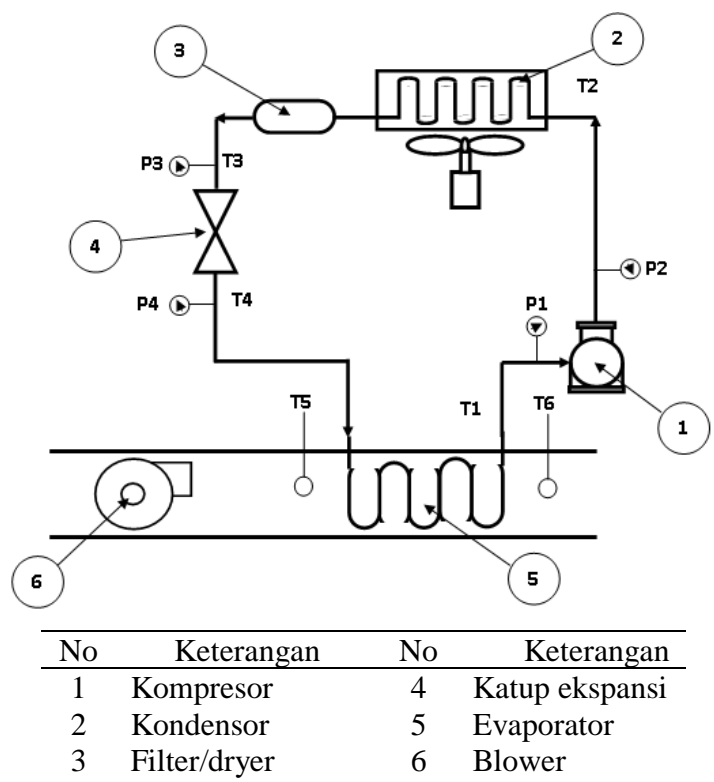

Gambar 1. Set up peralatan dan media uji

Selanjutnya, proses pengambilan data sesuai dengan diagram alir yang disajikan dalam Gambar 2 sebagai berikut.
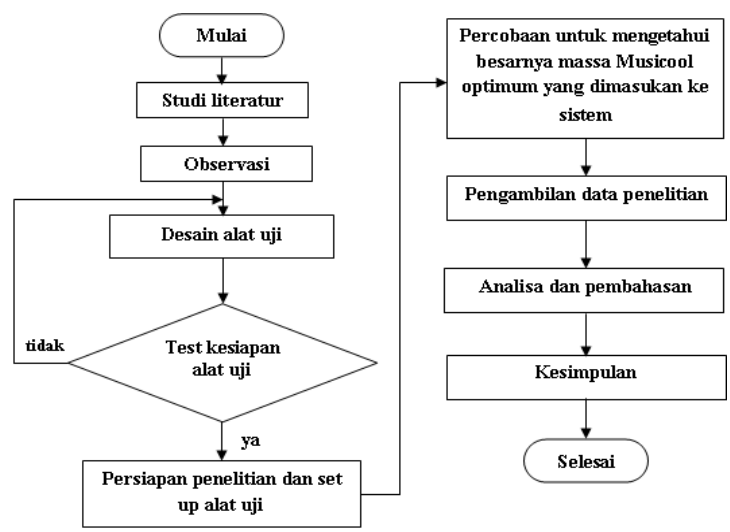

Gambar 2. Diagram alir peneltian

\section{HASIL DAN PEMBAHASAN}

Selama pengambilan data, temperatur refrigeran saat memasuki evaporator dan kondensor diamati. Begitu juga dengan tekanan refrigeran saat masuk dan keluar kompresor. Data data tersebut direkam pada kondisi transien dan kondisi tunak dengan penjelasan yang detail sebagai berikut. 


\section{Profil Temperatur Refrigeran Memasuki Evaporator}

Gambar 3 berikut menunjukkan ketercapaian temperatur refrigeran masuk evaporator atau keluar katup ekspansi untuk berbagai variasi konsentrasi $\mathrm{CO}_{2}$ dan kecepatan blower.
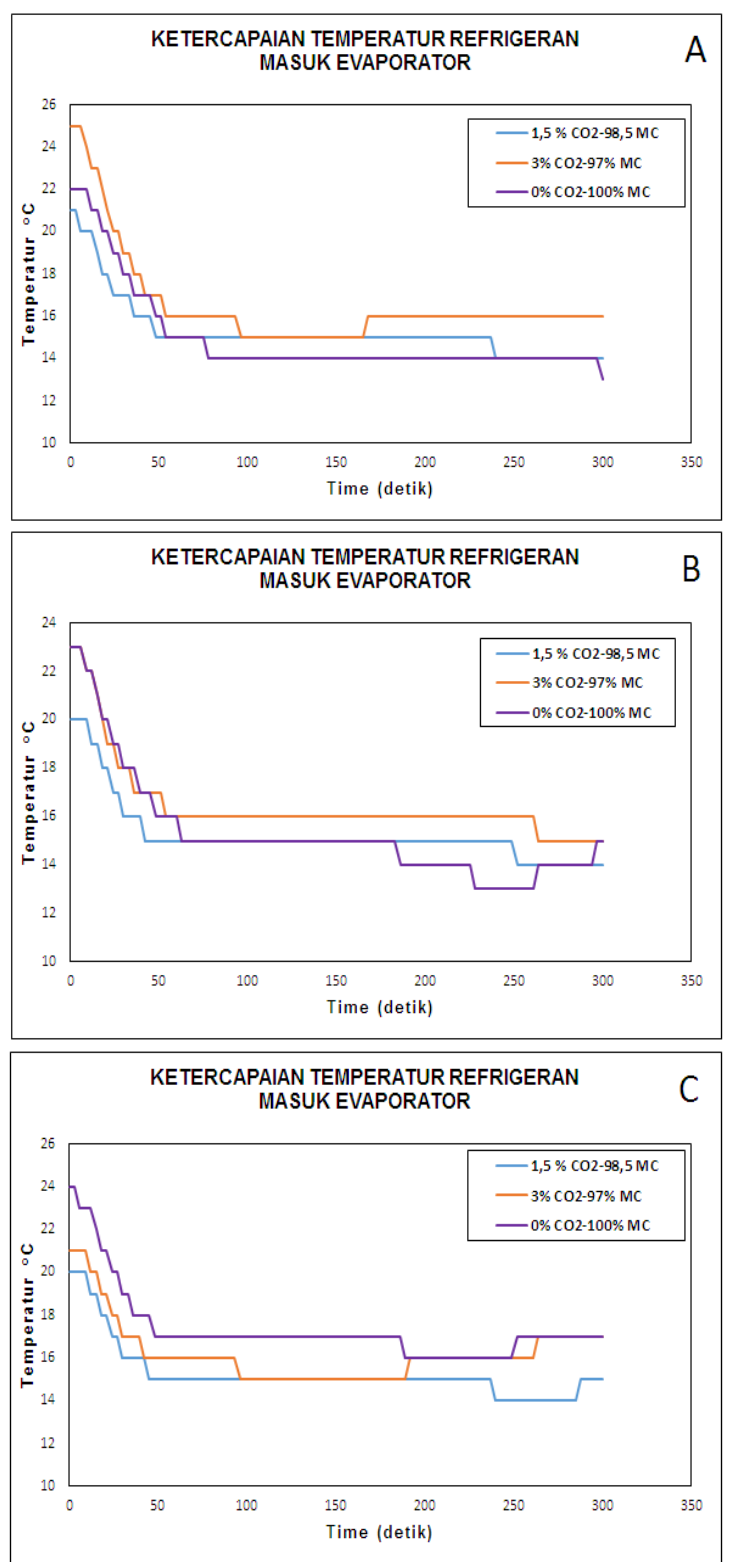

Gambar 3. Ketercapaian temperatur refrigeran masuk evaporator (A) 14755 CMM; (B) 17900 CMM; dan (C) 22850 CMM

Gambar 3 menunjukkan bahwa semakin besar konsentrasi $\mathrm{CO}_{2}$ maka semakin tinggi temperature keluar katup ekspansi. Hal tersebut karena terjadi kerugian throttling dan irreversibility yang cukup signifikan dengan bertambahnya konsentrasi $\mathrm{CO}_{2}$ selama proses ekspansi. Hal ini sesuai dengan hasil penelitian Dai et al. (2014) yang mengatakan bahwa salah satu faktor yang membatasi penggunaan refrigeran $\mathrm{CO}_{2}$ adalah kerugian throttling yang besar dan irreversibility yang mempengaruhi performa dari sistem secara keseluruhan.

Namun demikian, penggunaan refrigeran musicool 134 secara murni juga terjadi peningkatan temperatur masuk evaporator atau keluar katup ekspansi dengan semakin besarnya beban pendinginan. Terlihat dalam gambar 3 bahwa pada beban pendinginan dengan aliran massa udara $\left.\begin{array}{lll}\text { tertinggi } & (22850 & \mathrm{CMM}\end{array}\right)$ ketercapaian temperatur paling tinggi. Fenomena ini karena pada beban yang tinggi, katup ekspansi akan membuka lebih besar. Dengan demikian temperatur yang keluar akan lebih tinggi, hal tersebut juga membatu agar temperatur keluar evaporator berada pada fasa superheated sehingga mengurangi kerusakan kompresor.

\section{Profil Temperatur Refrigeran Masuk Kondensor}

Gambar 4 berikut menunjukkan ketercapaian temperatur refrigeran masuk kondensor atau keluar kompresor untuk berbagai variasi konsentrasi $\mathrm{CO}_{2}$ dan kecepatan blower. Dari gambar 4 dapat dilihat temperatur discharge kompresor musicool 134 lebih tinggi dari temperatur discharge kompresor campuran musicool 134 dan $\mathrm{CO}_{2}$. Karakteristik ini dikarenakan perbedaan boiling temperature yang berbeda antara musicool 134 dan $\mathrm{CO}_{2}$, yaitu $-31,5{ }^{\circ} \mathrm{C}$ dan $78,45{ }^{\circ} \mathrm{C}$, serta adanya perbedaan temperatur masuk kompresor, dimana fluida kerja dengan 100\% musicool 134 lebih tinggi.

Ketercapaian temperatur discharge kompresor diperoleh untuk beban pendinginan 17900 CMM (gambar 4B) memiliki temperatur yang lebih rendah, hal tersebut mengilustrasikan bahwa performa sistem lebih baik, karena kerja kompresor akan lebih rendah. Pada beban pendinginan tersebut dimungkinkan fluida kerja tidak terjadi superheating maupun penurunan temperatur keluar evaporator yang akan membuat kerja kompresor menjadi berat. 

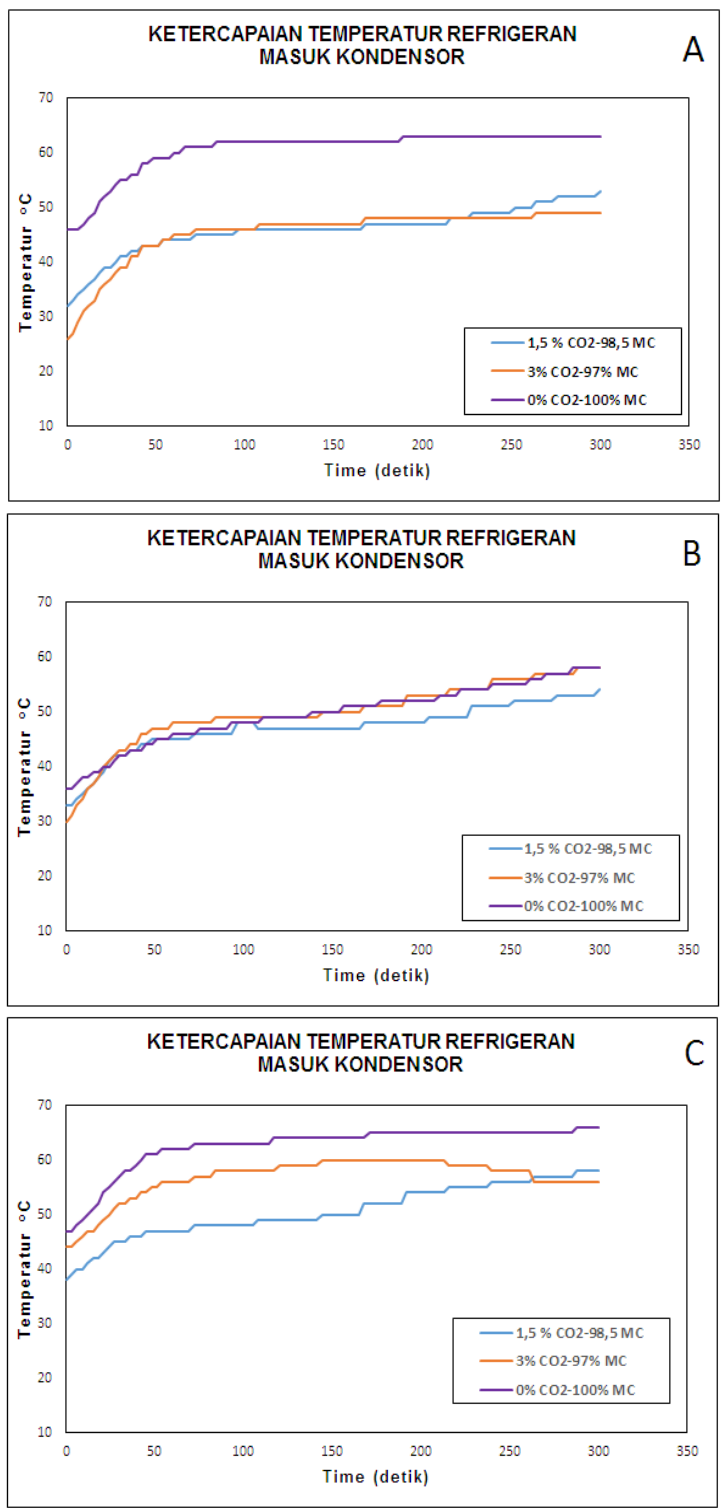

Gambar 4. Ketercapaian temperatur refrigerant masuk kondensor (A) $14755 \mathrm{CMM}$; (B) $17900 \mathrm{CMM}$; (C) $22850 \mathrm{CMM}$

\section{Tekanan Refrigeran Keluar Kompresor}

Gambar 5 menunjukkan ketercapaian tekanan refrigeran keluar kompresor untuk berbagai variasi konsentrasi $\mathrm{CO}_{2}$ dan kecepatan blower. Ketercapaian tekanan discharge dipengaruhi oleh karakteristik masing-masing refrigeran. Hasil penelitian ini memberikan ilustrasi bahwa setiap kenaikan konsentrasi $\mathrm{CO}_{2}$ akan meningkatkan tekanan di sisi keluar kompresor. Hal yang sama juga dikemukakan oleh Dai et al. (2014). Sehingga pada penggunaan refrigeran musicool $100 \%$ diperoleh tekanan discharge kompresor lebih rendah untuk semua beban pendinginan.
Namun demikian, jika dibandingkan terhadap beban pendinginan maka ketercapaian tekanan discharge kompresor optimal pada kondisi stabil diperoleh pada beban pendinginan dengan flowrate udara yang melintasi evaporator sebesar $17900 \mathrm{CMM}$ (gambar 5B), sehingga dengan tekanan kondensasi lebih rendah akan memiliki potensi performa sistem secara keseluruhan yang lebih baik.

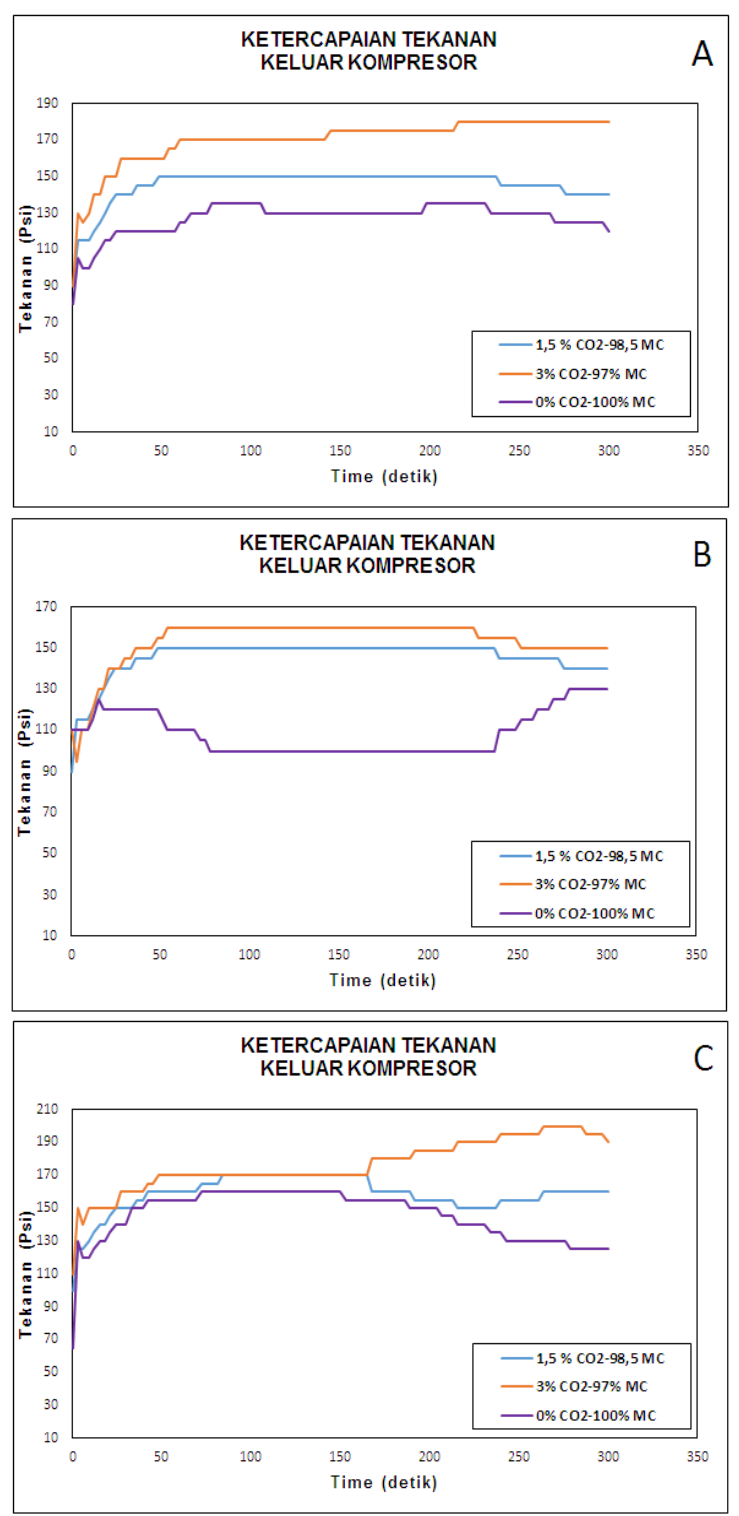

Gambar 5. Ketercapaian Tekanan refrigerant keluar Kompresor (A) 14755 CMM; ( B) 17900 CMM; (C) 22850 CMM

\section{Tekanan Refrigeran Masuk Kompresor}

Gambar 6 menunjukkan ketercapaian tekanan refrigeran masuk kompresor untuk berbagai variasi konsentrasi $\mathrm{CO}_{2}$ dan 
kecepatan blower. Ketercapaian tekanan dipengaruhi oleh konsentrasi $\mathrm{CO}_{2}$, terlihat pada Gambar 6 bahwa semakin besar konsentrasi $\mathrm{CO}_{2}$ maka semakin tinggi tekanan masuk kompresor. Dengan lebih tingginya tekanan masuk kompresor maka kerja kompresor akan lebih ringan. Ketercapaian tekanan masuk kompresor tidak terlepas dari kerja katup ekspansi. Hal tersebut karena dengan bertambahnya konsentrasi $\mathrm{CO}_{2}$ akan menurunkan volume spesifik refrigeran campuran sehingga akan menurunkan kerugian throttling yang cukup besar.
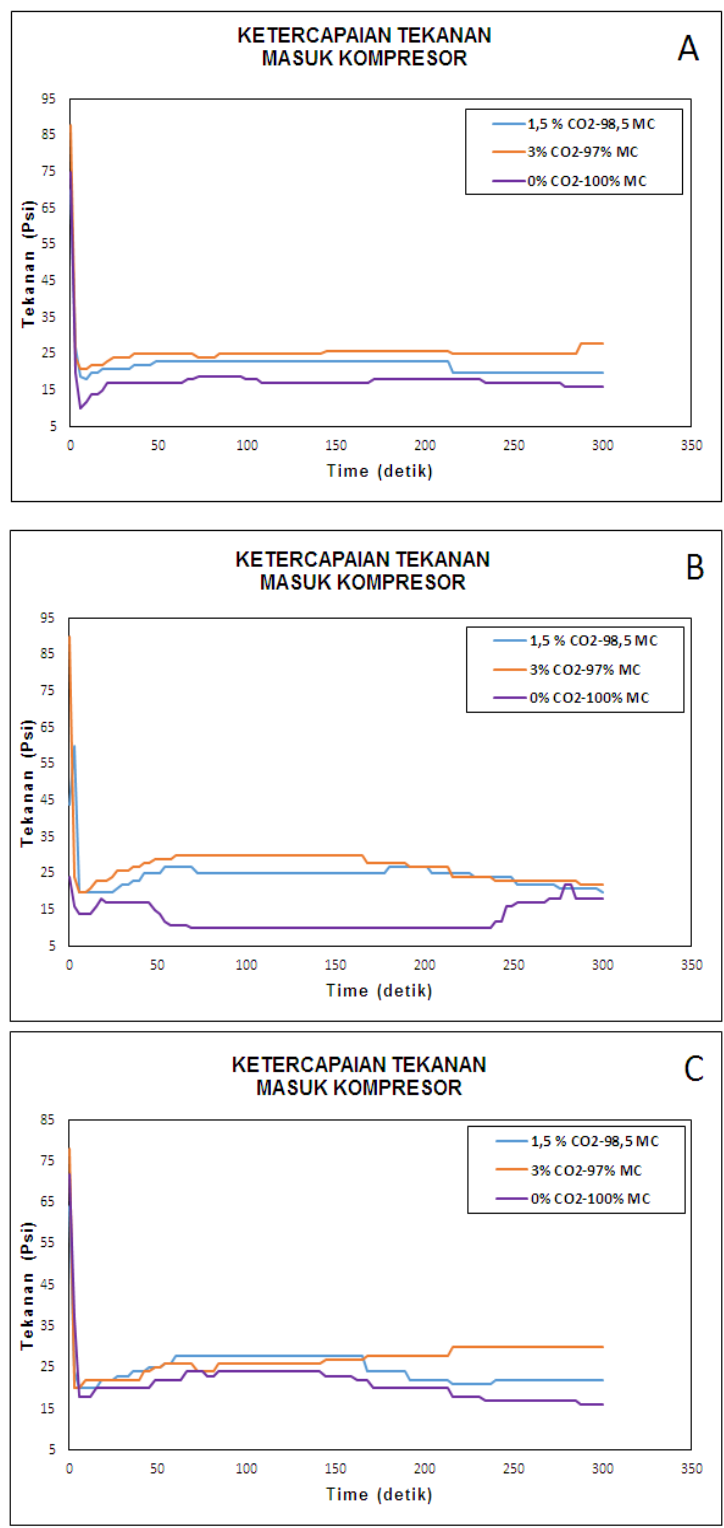

Gambar 6. Ketercapaian Tekanan refrigerant masuk Kompresor (A) 14755 CMM; (B) 17900 CMM; (C) 22850 CMM
Hal lain yang dapat dilihat dari gambar 6 adalah keterkaitan tekanan masuk kompresor dengan beban pendinginan, dimana semain besar beban maka semakin tinggi tekanan masuk kompresor. proses ini sangat tergantung dari kerja katup ekspansi, dimana fungsi katup ekspansi adalah mengatur supanya kondisi refrigeran keluar evaporator hanya sedikit superheated, sehingga ketika beban pendinginan meningkat maka katup ekspansi akan membuka lebih besar, hal ini supaya jumlah aliran refrigeran yang masuk evaporator menjadi lebih banyak untuk mengatasi beban pendinginan yang meningkat. Bukaan katup ekspansi yang bertambah besar akan menurunkan kerugian throttling sehingga tekanan yang keluar katup ekspansi akan sedikit lebih besar.

\section{KESIMPULAN}

Berdasarkan hasil penelitian yang dilakukan untuk mendapatkan karakteristik sistem refrigerasi kompresi uap menggunakan refrigeran campuran antara hidrokarbon (musicool 134) dan karbondioksida $\left(\mathrm{CO}_{2}\right)$ dengan variasi beban kecepatan blower dapat diambil beberapa kesimpulan seperti berikut ini :

a) Semakin besar konsentrasi $\mathrm{CO}_{2}$ maka semakin tinggi temperatur masuk evaporator atau keluar katup ekspansi.

b) Peningkatan beban pendinginan akan meningkatkan temperatur masuk evaporator atau keluar katup ekspansi.

c) Ketercapaian tekanan discharge dipengaruhi oleh karakteristik masingmasing refrigeran. Hasil penelitian ini memberikan ilustrasi bahwa setiap kenaikan konsentrasi $\mathrm{CO}_{2}$ akan meningkatkan tekanan di sisi keluar kompresor.

d) Temperatur discharge kompresor untuk refrigeran 100\% musicool 134 lebih tinggi dari temperatur discharge kompresor campuran musicool 134 dan $\mathrm{CO}_{2}$.

e) Ketercapaian temperatur discharge kompresor diperoleh untuk beban pendinginan $17900 \mathrm{CMM}$.

f) Semakin besar konsentrasi $\mathrm{CO}_{2}$ maka semakin tinggi tekanan masuk kompresor dan semakin besar beban maka semakin tinggi pula tekanan masuk kompresor. 


\section{UCAPAN TERIMAKASIH}

Penelitian ini dibiayai oleh DRPM Kemenristekdikti melalui hibah PDP tahun 2016 dan dikelola oleh Divisi Penelitian LP3M Universitas Muhammadiyah Magelang. Untuk itu diucapkan terimakasih pada kedua institusi. Para peneliti juga berterimaksih kepada mahasiswa yang telah membantu pembuatan set up eksperimen dan pengambilan data.

\section{DAFTAR PUSTAKA}

Agrawal, M.K. \& Matani, A.G., 2013. Evaluation of Vapour Compression Refrigeration System Using Different Refrigerants. International Journal of Engineering and Innovative Technology, 2(9), pp.86-92.

Alsaad, M.A. \& Hammad, M.A., 1998. The application of propane/butane mixture for domestic refrigerators. Applied Thermal Engineering, 18(9-10), pp.911-918.

Austin, N., Kumar, P.S. \& Kanthavelkumaran, N., 2012. Thermodynamic Optimization of Household Refrigerator Using Propane - Butane as Mixed Refrigerant. International Journal of Engineering Research and Applications, 2(6), pp.268-271.

Brown, J.S., Yana-motta, S.F. \& Domanski, P. a, 2002. Comparitive analysis of an automotive air conditioning systems operating with $\mathrm{CO} 2$ and R134a. International Journal of Refrigeration 25 (2002) 19-32, 25, pp.19-32.

Dai, B. et al., 2014. Thermodynamic performance assessment of carbon dioxide blends with low-global warming potential (GWP) working fluids for a heat pump water heater. International Journal of Refrigeration, 64, pp.942952.

Dalkilic, a. S. \& Wongwises, S., 2010. A performance comparison of vapourcompression refrigeration system using various alternative refrigerants. International Communications in Heat and Mass Transfer, 37(9), pp.13401349.

Globalindo Niaga Prima, Menggunakan Musicool Refrigerant yang Ramah Linkungan dan Hemat Listrik Pada
Mesin AC Sebagai Alternatif Pengganti Freon - Globalindo Niaga Prima. Available at: http://www.globalindoprima.com [Accessed February 10, 2017].

Han, X.H. et al., 2013. Cycle performances of the mixture HFC-161 + HFC-134a as the substitution of HFC-134a in automotive air conditioning systems. International Journal of Refrigeration, 36(3), pp.913-920.

Li, G. et al., 2014. Experimental investigation of energy and exergy performance of secondary loop automotive airconditioning systems using low-GWP (global warming potential) refrigerants. Energy, 68, pp.819-831.

Liao, S.Y. et al., 2005. Experimental study of flammability limits of natural gas-air mixture. Journal of Hazardous Materials, 119(1-3), pp.81-84.

Mahajan, R.Y. \& Borikar, S.A., 2014. Performance Evaluation of Domestic Refrigerator Using Hc- 12a Refrigerant as an Alternative Refrigerant to R12 And R134a. The International Journal Of Engineering And Science, 3(10), pp.26-37.

Nagalakshmi, K. \& Yadav, G.M., 2014. The Design and Performance Analysis of Refrigeration System Using R12 \& R134a Refrigerants. Journal of Engineering Research and Applications, 4(2), pp.638-643.

Pérez-García, V. et al., 2013. Comparative study of transcritical vapor compression configurations using $\mathrm{CO} 2$ as refrigeration mode base on simulation. Applied Thermal Engineering, 51(1-2), pp.1038-1046.

Sarkar, J. \& Bhattacharyya, S., 2009. Assessment of blends of $\mathrm{CO} 2$ with butane and isobutane as working fluids for heat pump applications. International Journal of Thermal Sciences, 48(7), pp.1460-1465.

Setiyo, M. et al., 2016. A simulation for predicting potential cooling effect on LPG-fuelled vehicles. In $A I P$ Conference Proceedings. American Institute of phisics, p. 30002. 
Setiyo, M. et al., 2017. Temperature Distribution of R-134a Through Aluminum and PTFE Expansion Valve on Automotive Air Conditioning Applications. ARPN Journal of Engineering and Applied Sciences, 12(4), pp.1046-1051.

United Nations, 1998. Kyoto Protocol To the United Nations Framework Convention and Climate Change,

Wang, K. et al., 2010. Review of secondary loop refrigeration systems. International Journal of Refrigeration, 33(2), pp.212234.
Wongwises, S. \& Chimres, N., 2005. Experimental study of hydrocarbon mixtures to replace HFC-134a in a domestic refrigerator. Energy Conversion and Management, 46, pp. 85-100.

Yadav, P. \& Sharma, A., 2015. Exergy Analysis of R134a Based Vapour Compression Refrigeration Tutor. In National Conference on Advances in Engineering, Technology and Management. Sadopur: Maharishi Markandeshwar University, pp. 73-77. 